\title{
A Casa de Máquinas da administração pública no enfrentamento à COVID-19
}

\author{
Fernando de Souza Coelho 1 \\ Victor Corrêa ${ }^{2}$ \\ Rafael Lincoln Lisboa ${ }^{1}$ \\ Sibelly $\operatorname{Resch}^{3}$
}

1 Universidade de São Paulo / Escola de Artes, Ciências e Humanidades, São Paulo / SP - Brasil

${ }^{2}$ Academia da Força Aérea, Pirassununga / SP - Brasil

${ }^{3}$ Universidade Federal de Mato Grosso do Sul, Campus de Naviraí, Naviraí / MS - Brasil

\begin{abstract}
O enfrentamento à COVID-19 no Brasil demanda estratégias e ações integradas e articuladas entre as três esferas de governo e seus diversos setores de políticas públicas para prestar serviços públicos essenciais e ofertar programas governamentais emergenciais. Para que essas ações públicas alcancem os cidadãos-usuários, as áreas-meio da administração pública, consideradas - metaforicamente - neste artigo como a Casa de Máquinas, entram em operação. Sob o prisma dessa dimensão intraorganizacional, este trabalho objetiva descrever e analisar as funções administrativas no ajuste do serviço funerário - elo final da cadeia de combate ao coronavírus em qualquer cidade. O locus empírico é o serviço funerário do município de São Paulo, escolhido pela sua magnitude e por ser monopólio do setor público. Usando-se da análise documental e da realização de entrevistas com gestores públicos locais, o artigo joga luz no back office pelas funcionalidades de finanças, recursos humanos, processos e tecnologia da informação (TI), compras e contratos, logística e operações, e comunicação/marketing, evidenciando as engrenagens das organizações públicas no contexto da crise sanitária e contribuindo para a reflexão sobre os pontos-chave que devem ser considerados em distintas realidades, ainda que com as limitações de uma análise de um processo em curso.
\end{abstract}

Palavras-chave: COVID-19; gestão pública; dimensão intraorganizacional; áreas-meio; serviço funerário.

\section{La 'Sala de Máquinas' de la administración pública en la lucha contra la COVID-19}

El enfrentamiento a la COVID-19 en Brasil requiere estrategias y acciones integradas y articuladas entre las tres esferas del gobierno y los diversos sectores de políticas públicas para prestar servicios públicos esenciales y ofrecer programas gubernamentales de emergencia. Para que estas acciones públicas lleguen a los ciudadanosusuarios, las áreas funcionales de la gestión pública, consideradas metafóricamente en este artículo como 'Sala de Máquinas', entran en operación. Bajo el prisma de esta dimensión intraorganizacional, este estudio tiene como objetivo describir y analizar las funciones administrativas en el ajuste del servicio funerario -el eslabón final de la cadena de combate al coronavirus en cualquier ciudad-. El locus empírico es el servicio funerario del municipio de São Paulo, elegido por su magnitud y por ser el monopolio del sector público. A través del análisis documental y de las entrevistas con gestores públicos locales, el artículo arroja luz sobre el back office por las funcionalidades de las finanzas, recursos humanos, procesos y tecnología de la información (TI), compras y contratos, logística y operaciones y comunicación/marketing, destacando los engranajes de las organizaciones públicas en el contexto de la crisis sanitaria y contribuyendo a reflexionar sobre los puntos clave que deben considerarse en diferentes realidades, aunque con las limitaciones de un análisis de un proceso en curso.

Palabras clave: COVID-19; gestión pública; dimensión intraorganizacional; áreas funcionales; servicio funerario. 


\section{The public administration's 'engine room' in the fight against COVID-19}

The fight against the COVID-19 pandemic in Brazil requires integrated and coordinated strategies and actions involving different public policy agencies in the local, state, and federal governments, delivering essential services and emergency programs. Such services rely on public administration's functional areas, designated in this work as the "engine room." The study uses this particular intra-organizational dimension to describe and analyze the administrative functions in the adjustment of the death care services in a municipality, as the final link in the fight against the SARS-CoV-2. The empirical locus is the death care service of São Paulo, Brazil. The service was chosen because it is a public sector monopoly and São Paulo because of the municipality's size - one of the biggest in the world. The research adopted documentary analysis and interviews with local public managers, examining the back office of public administration focusing on finance, human resources, processes and information technology, procurement and contracts, logistics and operations, and communication and marketing. The study discusses the mechanisms of public organizations in the context of the pandemic. It leads to a reflection on the key points of such a health crisis considering different realities, recognizing the limits of analyzing an ongoing phenomenon. Keywords: COVID-19; public management; intra-organizational dimension; functional areas; death care.

\section{INTRODUÇÃo}

O enfrentamento da crise sanitária estabelecida a partir da COVID-19 pôs em xeque - político e técnico - o processo decisório e as estruturas e processos governamentais em todo o mundo; afinal, são muitos os desafios adaptativos impostos pela pandemia à administração pública. A academia brasileira de gestão e políticas públicas, em face do coronavírus, contribuiu de imediato com várias análises - artigos de opinião, notas técnicas e relatórios de conjuntura - sobre os aspectos de polity, politics e policy no combate ao problema e suas consequências, sobretudo diante das diferentes tomadas de decisão dos atores políticos e distintas estratégias e ações dos governos na federação. Outrossim, sobressaiu uma agenda de pesquisa voltada para os impactos econômicos e efeitos sociais advindos da COVID-19, com investigações das políticas públicas de saúde, de assistência social e de educação que discutem e/ou orientam a prestação dos serviços públicos relacionados aos seus sistemas nacionais - SUS e SUAS, por exemplo.

Apesar do horizonte temporal curto, percebe-se, assim, que o debate sobre boas práticas, falhas e insucessos do setor público brasileiro no combate à pandemia tem focado mormente os aspectos político-estruturais, secundarizando as dimensões intraorganizacionais que operacionalizam, na acepção administrativa, o "Estado em ação". Neste contexto, este artigo joga luz em um tema por vezes relegado na gestão pública contemporânea: o papel das áreas-meio e suas áreas funcionais (Coelho \& Valadares, 2019) - um objeto de estudo inevitável para se compreender as respostas dos governos em termos do design e delivery de projetos e atividades pelo back office da administração pública. A retaguarda do Poder Executivo (quer seja na administração direta ou indireta) naturalmente é algo invisível aos cidadãos-usuários, tal como ocorre com as funções administrativas e seu staff perante clientes de uma organização privada.

Como locus empírico, escolheu-se o serviço funerário da Prefeitura Municipal de São Paulo (PMSP); um serviço público essencial na crise da COVID-19, recorrente na mídia nesse período (com reportagens sobre abertura de valas às pressas e duplicação dos enterros ${ }^{1}$ - muitos dos quais sem oportunidade de

\footnotetext{
${ }^{1}$ Segundo dados da Prefeitura Municipal de São Paulo, divulgados na primeira quinzena de junho de 2020, os sepultamentos em abril deste ano foram 8.296 contra 5.513 no mesmo mês de 2019; no último mês de maio, por sua vez, ocorreram 9.794 sepultamentos na capital ante 5.799 em maio do ano passado.
} 
velório) e inexplorado nas revistas da comunidade acadêmica de administração no Brasil. Na base Spell/ ANPAD, por exemplo, usando-se a busca por "serviços funerários", verifica-se uma lacuna: há quatro artigos científicos sobre o assunto e nenhum com abordagem da administração pública.

Assim, com um framework para a Casa de Máquinas nas organizações públicas, e baseado na análise documental (de publicações do Diário Oficial e de boletins do município) e na realização de entrevistas com gestores públicos da PMSP, este trabalho descreve e analisa as ações que reorganizaram emergencialmente o serviço funerário da cidade durante os meses de março e abril de 2020. A seguir, a seção 2 apresenta a ideia de Casa de Máquinas como metáfora para se visualizar e compreender o trabalho de natureza técnico-gerencial das áreas-meio das organizações públicas. Posteriormente, a seção 3 tanto contextualiza o serviço funerário como objeto de estudo quanto apresenta os procedimentos metodológicos usados na investigação. Na sequência, a seção 4 examina os problemas enfrentados e as soluções adotadas pelo serviço funerário da PMSP em cada área funcional; ademais, com os aprendizados do caso de São Paulo, refletimos sobre as distintas realidades de algumas capitais. A seção 5, à guisa de conclusão, sumariza os resultados deste trabalho, desvelando suas contribuições e limitações, e indica uma agenda de pesquisa.

\section{A CASA DE MÁQUINAS DA ADMINISTRAÇÃO PÚBLICA: METÁFORA E FRAMEWORK²}

Diante de uma crise sanitária como a da COVID-19, com impactos econômicos e efeitos sociais que, no caso do Brasil, sobrepuseram-se a uma crise política no governo federal, a retaguarda da administração pública torna-se, de fato, invisível. Porém, obviamente existem estruturas e processos intraorganizacionais na máquina pública, denominada neste artigo metaforicamente de "Casa de Máquinas" e representada pelas áreas-meio, seja no âmbito macrogovernamental, seja no âmbito das organizações públicas.

Academicamente, essa dimensão intraorganizacional no setor público, originária da escola clássica da administração pública, é visualizada na metáfora das organizações vistas como máquinas (Morgan, 1996) e estilizada na burocracia mecanicista orientada para a eficiência operacional e no movimento da Administrative Management- com seus princípios de design organizacional aplicado às organizações públicas (inaugurado com as obras de Luther Gulick e William Willoughby) - nos primórdios do século XX. Na história do Brasil, esses ideais surgem no setor público na década de 1930, com a criação do DASP no Estado Novo de Getúlio Vargas e a importância da racionalização administrativa aplicada ao orçamento público, à gestão de materiais/patrimônio e à organização de pessoal (Wahrlich, 1979).

Se no passado essas funções administrativas se referiam à reforma burocrático-weberiana da gestão governamental, no presente essa Casa de Máquinas se (re)posiciona na interdependência entre os atores públicos e privados e nos arranjos interorganizacionais que caracterizam a ambiência da governança pública (Ferlie, Lynn, \& Pollitt, 2007). Isto é, não é um sistema fechado - isolado, rígido e estanque - circunscrito à gestão (interna) dos órgãos públicos, mas um sistema aberto sobre o qual os princípios de gestão por resultados, foco no usuário-cidadão, transparência e modernização administrativa prescrevem o "how to" em torno da prestação de serviços públicos para a sociedade.

\footnotetext{
${ }^{2}$ Algumas das ideias desta seção foram gestadas, inicialmente, por três dos autores deste artigo em um artigo de opinião publicado no blog Gestão, Política \& Sociedade do Estadão - jornal O Estado de S. Paulo - no dia 27 de abril de 2020, intitulado "A Casa de Máquinas da Gestão Pública na Crise do Coronavírus: o aqui e agora das áreas-meio nas ações emergenciais dos governos”.
} 
Nesse panorama, as políticas de gestão pública (ou gestão como política pública) tornam-se molas mestras para a coordenação - coerente e constante - das diversas áreas funcionais que perfazem a gestão pública; em síntese, "son medios autorizados para intentar guiar, compeler y motivar la función pública en su conjunto, (...) [con] cambios deseados y realizados en las reglas y rutinas institucionales" (Barzelay, 2003, pp. 18-19).

$\mathrm{Na}$ Casa de Máquinas da administração pública, as "roldanas e engrenagens" são ativadas por sistemas e funções de natureza técnico-gerencial compostos de estruturas e processos que permitem a organização funcionar, como recursos financeiros, atribuição de responsabilidades, o gerenciamento e a alocação de pessoal, o processo comunicacional e o suprimento de materiais (Huerta, 2008). O subsistema técnico volta-se para a entrega da tarefa, e o subsistema gerencial, por sua vez, intermedeia a relação entre a organização pública e o cidadão-usuário, assim como a provisão dos recursos para a elaboração e execução do task management. Baseado em Lynn (2007), pode-se acrescentar a abordagem da gestão pública como arte, praticada por indivíduos (burocratas de médio escalão e servidores públicos do staff administrativo) em papéis gerenciais para a resolução de problemas. Nota-se que, diante do desafio de atuar em um cenário de pandemia, essa arte de interpretar problemas, compreender desafios e tomar decisões na urgência, desatando nós (conflitos políticos, aspectos jurídico-legais e sobrepeso do controle, por exemplo) e dirigindo equipes de trabalho, necessita estar apurada. A integração entre estrutura formal e o comportamento organizacional dos órgãos públicos, compreendendo a modelagem organizacional justaposta à improvisação de gestores públicos que contornam as patologias sistêmicas da burocracia, realça uma capacidade de gestão e liderança que suplanta a dicotomia estrutura-volição pela equalização (Cavalcanti, 2004).

Em suma, a questão que emerge para a Casa de Máquinas da administração pública na pandemia é: como ajustar suas engrenagens para responder às múltiplas crises advindas da COVID-19, gerindo satisfatoriamente as funcionalidades de finanças, recursos humanos, processos e tecnologia da informação (TI), compras e contratos, logística e operações, e comunicação e marketing?

Neste artigo, propõe-se um framework para a Casa de Máquinas da administração pública, ilustrado pela Figura 1. Parte-se do ambiente organizacional do setor público involucrado pelas políticas públicas, com diretrizes e normatizações que se desdobram em prestação de serviços públicos e programas governamentais. Na dimensão intraorganizacional, no nível meso, visualizamos as três perspectivas que se interpenetram na gestão dos órgãos e entidades do Poder Executivo e orientam suas funções administrativas. A perspectiva organizacional envolve a estrutura (arquitetura de gestão e padrão formal de autoridade e cargos) e os processos administrativos como tomada de decisão e comunicação; a perspectiva técnica abrange os métodos, instrumentos e ferramentas de trabalho que amparam o diagnóstico dos problemas, o processo decisório, a projeção de resultados e o cumprimento das ações; e a perspectiva gerencial compreende o pensar e o agir tecnopolítico para mobilizar capacidades organizacionais e alinhar atores em prol do estabelecimento de objetivos. No nível micro da dimensão intraorganizacional, manifesta-se a Casa de Máquinas concernente às áreas-meio; elas concretizam-se em funções que processam (na acepção fayolista de planejamento, organização, execução e controle) os recursos financeiros, humanos, materiais, tecnológicos e informacionais que instrumentalizam projetos e atividades de gestão pública que, por seu turno, permitem que governos e organizações públicas desempenhem suas ações. 


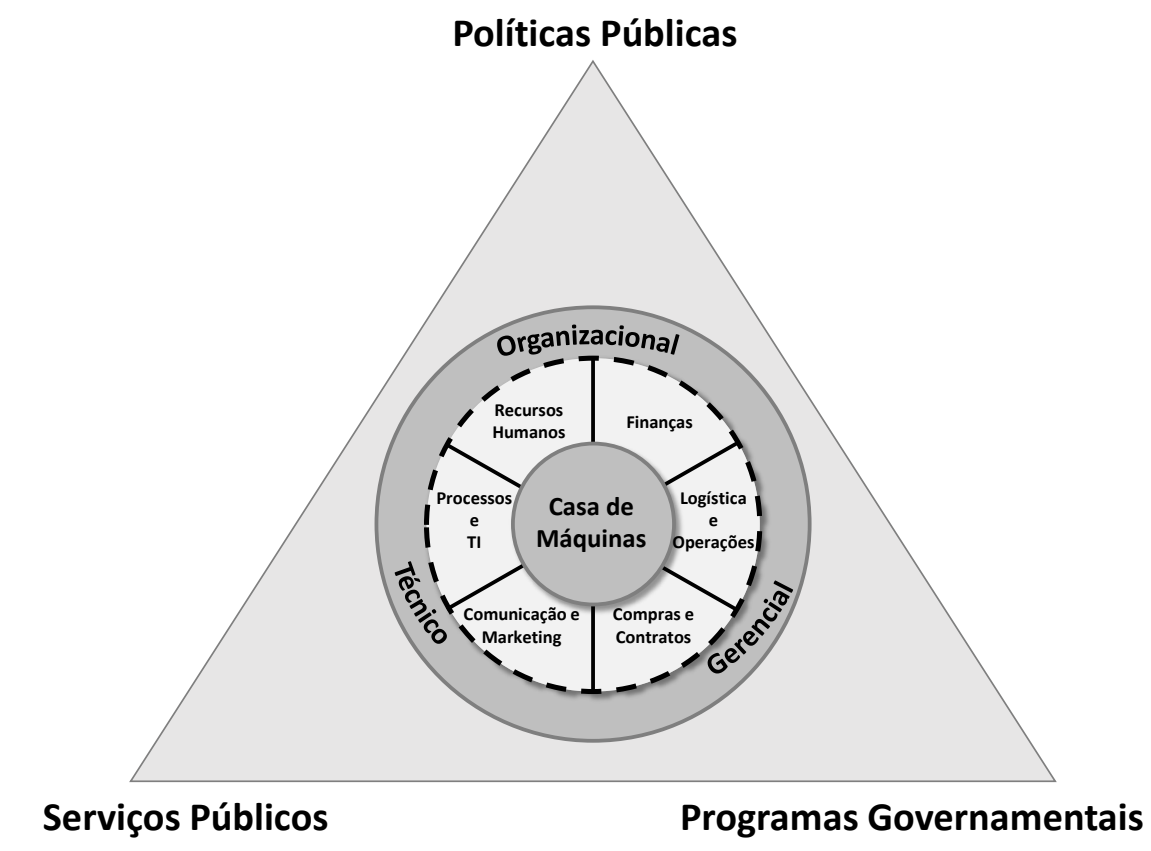

Fonte: Elaborada pelos autores.

Ressaltamos que não se trata de um modelo para avaliar - quantitativa e qualitativamente - a capacidade organizacional da Casa de Máquinas, mas, sim, de um prisma para trazer à baila os bastidores da gestão pública. Nesse caso, são as áreas funcionais e as funções administrativas da gestão governamental e de organizações públicas, resgatando a agenda de pesquisa que originou a disciplina de Administração Pública nos Estados Unidos entre o final do século XIX e meados do século XX - mais precisamente, entre o ensaio de Woodrow Wilson ("The Study of Administration", de 1887) e a obra de Dwight Waldo sobre "The Administrative State" publicada em 1948 (Denhardt, 2008).

\section{O SERVIÇO FUNERÁRIO DO MUNICíPIO DE SÃO PAULO: CONTEXTUALIZAÇÃO DO OBJETO DE ESTUDO E APRESENTAÇÃO DOS PROCEDIMENTOS METODOLÓGICOS}

O enfrentamento da COVID-19 no Brasil requer estratégias e ações congruentes de diversas áreas do governo e de uma governança multinível entre os entes da federação, visando a garantir o direito à vida e o bem-estar do cidadão. Entretanto, quando o efeito devastador da pandemia se avoluma em uma cidade, o poder público municipal deve também dar outra resposta: como proceder diante de tantos mortos?

Wuhan (CHI), Bérgamo (ITA), Nova York (EUA), Guayaquil (EQU) e Manaus (BRA) são exemplos de cidades pelo mundo que tiveram de lidar com o crescimento exponencial do número de óbitos, gerando uma sobrecarga nos serviços funerários e, consequentemente, um déficit na capacidade de resposta por parte dos governos locais. Com o número de mortes chegando a 
triplicar em relação à média mensal anterior à COVID-19 em muitas localidades, os efeitos da pandemia nos serviços funerários são severos, exigindo medidas emergenciais que, ao mesmo tempo, garantam segurança epidemiológica e promovam um momento de dignidade para o falecido e sua família. No entender de Zavattaro (2020), o gerenciamento de mortes em massa requer a atenção da comunidade acadêmica de Public Administration e pleiteia diligências das organizações públicas:

Na pesquisa em administração pública, ainda vemos uma lacuna quando se trata de gerenciamento de emergências, treinamento e planejamento relacionados a mortes decorridas. Geralmente, os pesquisadores se concentram em emoções positivas, como empatia e conexão (Patterson, 2001), mas a pandemia mostra que, como campo, precisamos prestar mais atenção ao papel das organizações públicas nas questões que envolvem a morte e o luto (Patterson, 2018). Embora as organizações públicas possam se preparar para uma crise que causará mortes, ainda há muito a aprender sobre exatamente como lidar com a logística de mortes, como vemos com a COVID-19 (Zavattaro, 2020, p. 1, tradução nossa).

Destarte, a monta do subsistema técnico-gerencial das organizações públicas para a prestação de serviços funerários é notória e deve(ria) abarcar toda a sequência de eventos em torno da morte e do luto. São necessárias orientações que contemplem respostas multidimensionais que estão além de manuais (como as publicações do Ministério da Saúde, 2020) sobre o manejo de corpos e procedimentos para enterros. Considerando o gerenciamento de situações de emergência que resultam em um elevado número de óbitos, o Comitê Internacional da Cruz Vermelha especificou seis elementos fundamentais que devem ser observados nos planos de contingência da COVID-19 em relação aos serviços funerários, a saber: (i) o aumento dos recursos humanos e materiais, bem como a construção de locais apropriados para as novas demandas de sepultamento; (ii) a priorização da segurança e do bem-estar das equipes envolvidas; (iii) a promoção do respeito e da dignidade dos falecidos e seus familiares; (iv) a manutenção das investigações médico-legais sobre mortes suspeitas, mantendo todas as precauções relacionadas à doença; (v) o contato acolhedor com a família do falecido e a comunicação adequada com a comunidade; e (vi) a permanente e efetiva coordenação entre todas as agências envolvidas no serviço (Finegan et al., 2020).

Esses elementos fundamentais são compreendidos como um sistema quando vistos a partir de eixos para a prestação do serviço funerário, vislumbrando assim os pontos-chave que devem ser levados em conta pelos governos locais em suas estratégias e ações para lidar com os óbitos, conforme o Quadro 1. O rol de questões que devem ser trabalhadas em cada um dos 8 eixos evidencia per se o quão imprescindível é uma estrutura macrogovernamental com competência de gestão para coordenar a integração de organizações públicas, redimensionar recursos, adequar legislações e elaborar projetos e atividades que respondam aos diferentes cenários decorrentes da crise sanitária para o "gerenciamento" dos processos subjacentes à morte e ao luto. 


\section{QUADRO 1 PONTOS-CHAVE PARA UMA RESPOSTA ADEQUADA NA PRESTAÇÃO DE SERVIÇOS FUNERÁRIOS}

\begin{tabular}{|c|c|}
\hline Eixos & Estratégias e ações \\
\hline Gestão e coordenação & $\begin{array}{l}\text { - Identificar responsáveis nas diversas frentes de trabalho; } \\
\text { - Atribuir papéis aos envolvidos na cadeia de serviço (identificação, exames pós-morte, } \\
\text { transporte, armazenamento, sepultamento, registro de óbito, atenção e informações às } \\
\text { famílias); } \\
\text { - Realizar abordagem multiagência, incluindo gestores de hospitais, autoridades religiosas, } \\
\text { gestores de cemitérios e iniciativa privada; } \\
\text { - Adequar procedimentos e recomendações; } \\
\text { - Oferecer assistência aos trabalhadores envolvidos na linha de frente; } \\
\text { - Garantir a quantidade de recursos necessários (infraestrutura, humanos, financeiros e } \\
\text { materiais); } \\
\text { - Avaliar os riscos envolvidos nas ações. }\end{array}$ \\
\hline Recuperação e transporte & $\begin{array}{l}\text { - Atentar para as legislações e recomendações pertinentes; } \\
\text { - Definir meios de transporte e destinos para os corpos; } \\
\text { - Planejar alternativas para possíveis gargalos na capacidade do sistema. }\end{array}$ \\
\hline Registro de óbito & $\begin{array}{l}\text { - Definir orientações específicas e responsabilidades para a documentação necessária; } \\
\text { - Considerar a capacidade reduzida dos órgãos públicos diante das medidas de isolamento } \\
\text { social. }\end{array}$ \\
\hline Aspectos médico-legais & $\begin{array}{l}\text { - Definir locais adequados para autópsias; } \\
\text { - Garantir informações adequadas às famílias quanto a procedimentos, prazos e condições } \\
\text { de liberação do corpo para enterro ou cremação. }\end{array}$ \\
\hline Armazenamento dos corpos & $\begin{array}{l}\text { - Considerar necessidade de armazenamento dos corpos devido à superlotação do sistema; } \\
\text { - Definir locais para armazenamento de corpos que estão aguardando exames; } \\
\text { - Considerar o apoio de órgãos públicos (universidade e unidades militares) e privados para } \\
\text { suprir demandas; } \\
\text { - Dimensionar recursos necessários para o armazenamento temporário; } \\
\text { - Definir procedimentos para identificação dos corpos armazenados. }\end{array}$ \\
\hline $\begin{array}{l}\text { Velório e assistência para as } \\
\text { famílias }\end{array}$ & $\begin{array}{l}\text { - Adequar os procedimentos para o velório, conforme recomendações sanitárias; } \\
\text { - Considerar os aspectos culturais e religiosos do contexto para o ritual de despedida; } \\
\text { - Dialogar com a família com o devido acolhimento e explicação dos procedimentos a serem } \\
\text { adotados no serviço funerário; } \\
\text { - Oferecer apoio psicológico aos parentes para lidarem com a angústia e a dor do luto. }\end{array}$ \\
\hline Enterro ou cremação & - Adequar a legislação e os procedimentos para agilizar as autorizações. \\
\hline Repatriação de corpos & $\begin{array}{l}\text { - Verificar regulamentações e procedimentos internacionais, coordenando ações para agilizar } \\
\text { processos e diminuir os impactos para os familiares. }\end{array}$ \\
\hline
\end{tabular}

Fonte: Elaborado pelos autores baseado em Finegan et al. (2020).

Indubitavelmente, olhar para o serviço funerário como um serviço público essencial na pandemia, que está no "elo final" da cadeia do enfrentamento da crise, constitui um objeto de 
estudo que contribui para elucidar o funcionamento da Casa de Máquinas na administração pública. Tomando o caso da cidade de São Paulo, em que o serviço funerário até então era monopólio da prefeitura, é factível analisar e descrever as ações levadas a cabo em cada área-meio. O Quadro 2 compendia algumas informações sobre a história e a organização do serviço funerário como serviço público da PMSP.

Para efeitos comparativos da alteração da demanda e da urgência das ações, basta relatar que, na década atual, a cidade realiza cerca de 240 sepultamentos por dia (Prefeitura de São Paulo, 2020) e previu ações - durante o mês de abril de 2020 - para aumentar a capacidade para 400 sepultamentos por dia. Se tomarmos o caso da cidade de Nova York para comparação, considerando as similaridades com a cidade de São Paulo, a cidade norte-americana atingiu o pico de mortes no dia 07 de abril de 2020, registrando 556 óbitos (New York City, 2020), impondo a necessidade, por exemplo, de sepultamento dos falecidos em valas comuns. Registra-se a importância da prestação do serviço funerário com a devida conformidade sanitária e celeridade, atributos indispensáveis para o próprio controle da pandemia. Em suma, enxergando-o sob a ótica de uma "cadeia de atendimento" no enfrentamento da COVID-19, em uma conjuntura de enorme possibilidade de contágio em que a mortalidade é algo inexorável, o poder público deve atentar-se a esse "elo final" com a mesma monta das ações de prevenção e combate.

\section{QUADRO 2 O SERVIÇO FUNERÁRIO DO MUNICÍPIO DE SÃO PAULO: UMA BREVE CONTEXTUALIZAÇÃO}

0 Serviço Funerário do Município de São Paulo (SFMSP), autarquia criada em 1958, é responsável pela gestão de 22 cemitérios municipais, 18 velórios e um crematório (Prefeitura de São Paulo, 2020), possuindo a exclusividade sobre toda contratação de serviço funerário na cidade, abrangendo desde as atividades de remoção de corpos para velório até o sepultamento e/ou cremação. Assim, por intermédio de uma das 12 agências funerárias da localidade, os usuários precisam pagar as taxas relativas ao tipo de homenagem que irão realizar ao falecido, com cobranças para os diversos serviços inerentes ao processo, como o caixão utilizado, 0 carro para remoção, os enfeites e paramentos utilizados, bem como os aluguéis do jazigo em que o corpo é sepultado ou as urnas para as cinzas, com variações de valores conforme as categorias escolhidas.

Destaca-se que o SFMSP é a maior autarquia da prefeitura, contando com quase dois mil servidores públicos (maiormente alocados em atividades operacionais) e dirigida por um Superintendente e um Conselho Deliberativo e Fiscal, composto de quatro membros. Tais cargos, de livre nomeação por parte do prefeito, por vezes podem ser utilizados para o fisiologismo político, haja vista ser um serviço cuja arrecadação é certa e constante, embora de menor prestígio e importância estratégica se comparado com os demais órgãos e entidades do poder público municipal.

Denúncias datadas desde a década de 1980 trouxeram à tona casos de corrupção de agentes públicos e também de funcionários de funerárias privadas que prometem facilidades às famílias que buscam o serviço público. Em 2015, por exemplo, o Ministério Público do Estado de São Paulo ea Controladoria Geral do Município de São Paulo realizaram investigações para identificar e responsabilizar servidores públicos envolvidos em denúncias de corrupção. 
Diante dos constantes casos de irregularidades e sob o argumento de promover maior eficiência administrativa no serviço funerário, em 2017, ainda na gestão do prefeito João Dória (2017-2018), foram iniciados os trabalhos para a concessão do SFMSP para a iniciativa privada. Já sob a gestão de Bruno Covas (2018-2020), apesar dos avanços nas tratativas legais quanto à concessão, os trâmites para a licitação foram adiados por conta da pandemia. Ressalta-se que o processo de concessão é alvo de divergências junto ao Tribunal de Contas do Município de São Paulo (TCM-SP), que já suspendeu o edital de concorrência três vezes. Também são frequentes os protestos por parte do Sindicato dos Trabalhadores na Administração Pública e Autarquias no Município de São Paulo (SINDSEP), com a alegação de que houve um processo contínuo e deliberado de sucateamento do serviço funerário para justiçar a sua concessão e substituir o monopólio público por um monopólio privado.

Vale salientar ainda que esse modelo de monopólio estatal do SFMSP, atíico para esse tipo de serviço, foi flexibilizado pela prefeitura em 24 de abril, conforme Decreto 59.372/2020, de modo a permitir que os velórios e sepultamentos nos cemitérios privados não necessitem mais da intermediação do poder público, buscando agilizar 0 atendimento das demandas pelo período em que perdurar a situação de emergência e o estado de calamidade por conta da pandemia.

Fonte: Elaborado pelos autores baseado em Prefeitura de São Paulo (2020), TCM-SP (2020), Rodrigues (2019), SINDSEP (2019), Castro (2014) e Porfírio (2006).

Desde que foi declarada a situação de emergência no Município de São Paulo, conforme Decreto Municipal no 59.283, em 16 de março de 2020, uma série de medidas impactaram o funcionamento dos serviços públicos, incluindo os serviços funerários. Com a imediata predição do cenário do aumento do número de óbitos, outras normatizações foram estabelecidas, sobretudo a partir das decisões de âmbito estadual, como o Decreto Estadual no 64.880, de 20 de março de 2020, e a Resolução SS-32, emitida pela Secretaria Estadual de Saúde. Ambos os documentos contêm recomendações claras sobre o correto manejo, preparo, acondicionamento, identificação e transporte dos corpos, além de dispor de orientações para os profissionais implicados nesses procedimentos.

Diante do crescimento da curva de casos do coronavírus e mortes decorrentes na cidade, em 15 de abril, conforme Decreto Municipal no 59.358, foi criado o Grupo Executivo Intersecretarial [GEI], com o "objetivo de planejar, propor, acompanhar e articular as ações relativas aos procedimentos preparatórios e de realização das inumações decorrentes de óbitos pela COVID-19” (GEI, 2020, p. 1), buscando agrupar esforços no enfrentamento da crise. Logo, decisões estratégicas do GEI balizaram ações no sistema técnico-operacional do SFMSP e demais organizações públicas vinculadas a essa força-tarefa, reorientando, por conseguinte, o funcionamento das áreas-meio - isto é, da Casa de Máquinas.

Enfim, presumindo que a pandemia provocou uma série de mudanças no funcionamento do SFMSP, organizamos um caminho metodológico para coletar dados e informações que permitissem descrever e analisar ocorrências e ajustes no back office do serviço funerário, ou seja, nas funções administrativas que estão na retaguarda do atendimento às demandas das famílias das vítimas fatais da COVID-19. Dado que o fenômeno observado é corrente e recente, de modo que inúmeras decisões e ações se sucedem na administração pública ao mesmo tempo em que a pesquisa ocorre, os métodos qualitativos empregados buscaram assegurar-se de critérios de validade e confiabilidade (Paiva, Leão, \& Mello, 2011). A análise documental baseou-se em fontes primárias, a partir das edições do Diário Oficial do Município de São Paulo do mês de abril, coletando informações acerca de eventos com impactos ou efeitos para o SFMSP, e fontes secundárias, como os boletins emitidos periodicamente 
pela prefeitura, com dados organizados e sistematizados pelos gestores públicos locais. Ademais, foram realizadas duas entrevistas semiestruturadas com dirigentes públicos - um do SFMSP e um do grupo gestor de informações que assessora o $\mathrm{GEI}^{3}$.

Usamos triangulação a partir das distintas fontes (Ollaik \& Ziller, 2011). Apesar de ambos os documentos serem de autoria da PMSP, nos Diários Oficiais não há interpretação dos dados, apenas a publicidade acerca de atos administrativos como contratações emergenciais, remanejamentos de pessoal e suplementações de crédito. Complementarmente, a triangulação foi realizada com as entrevistas com os dois dirigentes públicos, cotejando os dados e as informações documentais com as opiniões e a vivência de quem estava (re)orientando a Casa de Máquinas do SFMSP, aumentando a confiabilidade e a validade da investigação.

\section{A CASA DE MÁQUINAS DO SERVIÇO FUNERÁRIO DO MUNICÍPIO DE SÃO PAULO}

A exposição e discussão das ações no SFMSP por áreas-meio, a seguir, descortinam os nexos do desígnio e operação desse serviço público com as funções administrativas da gestão pública, exteriorizando o funcionamento da Casa de Máquinas por meio da questão: como as estratégias da PMSP de enfrentamento à COVID-19 se traduziram tático-operacionalmente no serviço funerário local?

\subsection{As ações tático-operacionais por área funcional}

Nesta subseção, são esmiuçadas as ações tático-operacionais que envolveram áreas-meio da gestão pública relativas aos meses de março e abril de 2020, para atender ao inevitável aumento da demanda. De antemão, é mister frisar que as ações tiveram como mola mestra a pandemia (supracitado Decreto Municipal no 59.283, de 16 de março de 2020). Em outras palavras, não havia estratégia ou curso de ação destinados para situações de desastre, mesmo com o primeiro caso de Wuhan (CHI) noticiado em 31 de dezembro de 2019 e a declaração de emergência internacional pela Organização Mundial da Saúde (OMS) em 30 de janeiro de 2020.

Logo, as respostas do poder público do país diante dos eventos inesperados foram apenas reativas, resultando em menor coerência e eficácia (McGuire \& Schneck, 2010) do que se integrassem um plano prévio. Vejamos, então, como as diversas áreas funcionais (finanças, recursos humanos, processos e tecnologia da informação, compras e contratos, logística e operações, e comunicação/marketing) que suportam os serviços funerários da PMSP foram amoldadas diante da situação emergencial.

\subsubsection{Finanças}

Analisando as contas públicas, a chave do cofre que destrava o desenrolar das demais ações, a partir das despesas correntes e de capital consolidadas até o dia 30 de abril de 2020, é possível averiguar o volume significativo de recursos alusivos ao serviço funerário, vide Tabela 1:

\footnotetext{
${ }^{3} \mathrm{O}$ Grupo Gestor de Informações tem o papel de prestar apoio técnico ao Grupo Executivo Intersecretarial (GEI) no tocante à estratégia de contingência funerária municipal durante a pandemia. Embora sua composição aconteceu informalmente no início do mês de abril, sua formalização ocorreu somente pela Portaria no 34 da Secretaria Municipal de Subprefeituras, de 19 de maio de 2020.
} 


\section{TABELA 1 RELATÓRIO DE DESPESAS POR NATUREZA DO SERVIÇO FUNERÁRIO DO MUNICÍPIO} DE SÃO PAULO

\begin{tabular}{|c|c|c|c|c|c|}
\hline $\begin{array}{l}\text { Natureza da } \\
\text { despesa }\end{array}$ & $\begin{array}{c}\text { Orçado inicial } \\
\text { (R\$) }\end{array}$ & Orçado atualizado (R\$) & Empenhado (R\$) & Liquidado (R\$) & Pago exercício (R\$) \\
\hline $\begin{array}{l}\text { Despesas } \\
\text { Correntes }\end{array}$ & $184.590 .000,00$ & $221.081 .596,18$ & $110.966 .720,65$ & $38.501 .391,68$ & $33.627 .414,24$ \\
\hline $\begin{array}{l}\text { Despesas de } \\
\text { Capital }\end{array}$ & $1.510 .000,00$ & $4.420 .580,00$ & $2.678 .913,95$ & $20.099,95$ & $20.099,95$ \\
\hline Totais & $186.100 .000,00$ & $225.502 .176,18$ & $113.645 .634,60$ & $38.521 .491,63$ & $33.647 .514,19$ \\
\hline
\end{tabular}

Fonte: Prefeitura da Cidade de São Paulo (2020).

A comparação entre os valores orçados inicialmente e os atualizados revelam o incremento de $\mathrm{R} \$ 36.491 .596,20$ nas despesas correntes e de $\mathrm{R} \$ 2.910 .580,00$ nas despesas de capital, totalizando $\mathrm{R} \$ 39.402 .176,20$, um aumento de pouco mais de $20 \%$ no orçamento da entidade. Com a suplementação de crédito na cifra dos $\mathrm{R} \$ 40$ milhões, a organização pública incrementou sua capacidade financeira para promover as adaptações necessárias, sustentando assim as decisões e ações subsequentes.

\subsubsection{Recursos Humanos}

Em relação aos recursos humanos, é possível verificar um redimensionamento da força de trabalho. Diante do aumento da demanda pelos serviços funerários, em 09 de abril de 2020, a prefeitura contratou emergencialmente 220 trabalhadores braçais para realização de sepultamentos nos 22 cemitérios municipais. Essa contratação emergencial representou um custo de $\mathrm{R} \$ \mathbf{8 . 9 6 0 . 9 0 3 , 4 0}$ aos cofres públicos. Havia ainda a previsão para novas contratações emergenciais, caso houvesse a necessidade de realização de sepultamentos noturnos diante da possibilidade de um crescimento vertiginoso do número de óbitos na cidade.

Cumpre sublinhar que, caso houvesse a necessidade de aumento do número de sepultamentos, mas sem riscos para os servidores públicos, o número de contratações seria menor, isso porque 154 sepultadores foram afastados por pertencer ao grupo de risco, configurando mais uma excepcionalidade da crise.

Complementarmente, para o suporte à gestão, alguns servidores foram transferidos de outras secretarias para prestar apoio às atividades do SFMSP, ampliando a equipe de gerenciamento para atividades e projetos administrativo-burocráticos.

\subsubsection{Processos e Tecnologia da Informação}

A dinamização dos processos e o uso da tecnologia da informação como suporte às decisões que devem ser tomadas ocorre, sobretudo, a partir da integração dos serviços no Centro Integrado 
de Controle do Estado de São Paulo (CICC). O CICC, criado em 2014 para atender à demanda da Copa do Mundo, e que teve suas atividades mantidas desde então, integra as forças de segurança, defesa civil e proteção do Estado de São Paulo (Polícia Civil do Estado de São Paulo, 2020). Durante a crise, o Serviço Funerário Municipal também passou a trabalhar de maneira integrada aos demais órgãos, como Polícia Civil, Corpo de Bombeiros e Serviço de Atendimento Móvel de Urgência (SAMU), formando uma rede de colaboração e suporte informacional. Assim, agilizou-se a obtenção das informações sobre os óbitos, que pode advir de diversas fontes, foi agilizada, possibilitando a análise sobre os cenários que afetam a capacidade operacional de maneira imediata.

Outra alteração relacionada aos processos (e também à logística do sistema) é a ampliação das permissões para lavração de declaração de óbitos, uma vez que os médicos do Serviço de Atendimento Móvel de Urgência (SAMU) estavam sobrecarregados com tais funções, deixando de atender outras emergências. Para isso, a legislação ampliou para os médicos integrantes da Polícia Militar, Forças Armadas e Corpo de Bombeiros a permissão para tal ato, desafogando o SAMU.

É igualmente válido citar a flexibilização do monopólio do Serviço Funerário Municipal, alterando a lógica do sistema para que os serviços pudessem ser prestados diretamente por empresas credenciadas e contratadas pelas famílias, sem passar pela autarquia municipal. Tal fato simplificou os processos e agilizou os trâmites para as famílias.

\subsubsection{Compras e contratos}

A Lei Federal 13.979, de 06 de fevereiro de 2020, entre outras medidas, prevê a dispensa de licitação para aquisição de bens, serviços (inclusive de engenharia) e insumos destinados ao enfrentamento da emergência de saúde pública de importância internacional decorrente do coronavírus. Seguindo a legislação federal, o Decreto n 59.283 da PMSP também prevê a dispensa de licitação para o enfrentamento da situação de emergência causada pela pandemia.

Desde a publicação do referido decreto, o município pôde iniciar os processos de compra em caráter emergencial, realizando a aquisição emergencial de insumos e materiais, bem como a contratação de serviços para atender ao aumento do número de óbitos no município de acordo com as diretrizes para manejo e seguimento dos casos de óbito, em conformidade com a Resolução SS-32. Para o manuseio dos corpos, recomenda-se o uso de Equipamentos de Proteção Individual (EPIs): luvas de procedimento dupla interpostas com material à prova de corte; roupa resistente a fluidos ou impermeável; avental à prova d'água e óculos largos de proteção ou viseiras de proteção; máscaras de proteção; e calçados fechados. Visando a atender a essas recomendações, identificou-se que o município adquiriu emergencialmente, no início de abril, máscaras descartáveis no valor de $\mathrm{R} \$ 243.600,00$ e, em meados do mesmo mês, 3 mil unidades de macacão específico para evitar o contágio de doenças nos servidores que manuseiam os corpos. Para o acondicionamento dos corpos, a prefeitura fez a aquisição emergencial de 19,4 mil unidades de mantos protetores, com o valor de $\mathrm{R} \$ 992.300,00$. Os contratos firmados para o fornecimento de urnas somaram $\mathrm{R} \$ 11.213 .087,01$, totalizando 27.590 urnas previstas para 3 dos 4 contratos firmados. Também foi adquirido o sistema Eco No-leak de guarda de restos mortais, com operações de abertura, sepultamento, fechamento e exumação para uso no "Cemitério Vertical”, totalizando R $2.658 .814,00$.

REVISta de AdMinistração Pública | Rio de Janeiro 54(4):839-859, jul. - ago. 2020 
Além dos EPIs e materiais para manejo e acondicionamento dos corpos, a Prefeitura de São Paulo também adquiriu material de construção para uso nas necrópoles e no setor de manutenção do SFMSP. O processo licitatório obteve o valor total global anual de $\mathrm{R} \$ 531.338,88$. Além dos custos com a aquisição de equipamentos e materiais, a PMSP também autorizou um aditivo de $25 \%$ no contrato das empresas que atuam na prestação de serviços de limpeza, asseio e conservação predial nas unidades administrativas, agências e velórios que compõem a estrutura física da autarquia. Os aditivos dos três contratos identificados somam $\mathrm{R} \$ 1.080 .311,81$.

Nota-se que nem todos os produtos sugeridos pela Resolução SS-32 foram identificados no processo de compras até o final de abril, cabendo análises posteriores sobre tais certames. Ademais, denúncias foram feitas pelo Sindicato dos Servidores Municipais de São Paulo sobre a falta de materiais para todos os trabalhadores, exigindo a utilização de materiais descartáveis por mais de uma vez. Apesar desse tipo de análise não ser o objetivo deste artigo, cabe reforçar essa situação que atinge quase todos os cargos da burocracia de nível de rua que estão na linha de frente na prestação dos serviços públicos essenciais como saúde, segurança, limpeza urbana e assistência social.

De todo modo, somando as aquisições realizadas pelo SFMSP entre meados de março e o final de abril, houve o desembolso de um total de R $\$ 16.719 .451,70$ com insumos, materiais e EPIs.

\subsubsection{Logística e operações}

A gestão logística e de operações do SFMSP exigiu alguns variados rearranjos. Foram desenhados Centros Logísticos localizados dentro dos cemitérios - um instalado durante o mês de abril e outros dois previstos em caso de pressão operacional futura - para realização dos procedimentos adequados com as vítimas da COVID-19. Nesse espaço, instalou-se uma câmara refrigerada para armazenamento temporário de corpos. Está prevista, adicionalmente, a locação de até 8 câmaras refrigeradas para o município, se houver necessidade.

Outrossim, para aumentar a capacidade das operações, foram abertas 13 mil novas valas para sepultamento em 3 cemitérios considerados estratégicos. O transporte de corpos também sofreu alterações, com mais 20 veículos sendo contratados para a realização do traslado dos corpos.

Apesar dos esforços envidados pela PMSP para a realização das operações do serviço funerário dentro dos padrões e recomendações das autoridades sanitárias, em abril foi contumaz a demora do mercado interno e externo em atender o volume de compras dos governos, em face da explosão da procura, mostrando quão útil é as organizações públicas manterem estoque de suprimentos cruciais para situações imprevistas.

\subsubsection{Comunicação e marketing}

As alterações nos procedimentos relacionados ao serviço funerário exigiram uma ampla divulgação intraorganizacional. Assim, é fundamental a comunicação interna com os servidores sobre as normas de segurança, o uso de EPIs e os novos procedimentos na rotina de trabalho. Além dos decretos e comunicados formais, foram usados reforços via diálogo pelas chefias e canais informais de comunicação, como grupos de trocas de mensagens. Ressalta-se que no SFMSP os trabalhadores da 
linha de frente já usavam equipamentos de proteção; ainda que mais simples, já estavam habituados com essa rotina.

Externamente, a sociedade também precisou ser informada sobre os novos procedimentos. Além das divulgações a partir da imprensa e das mídias digitais, os agentes públicos e privados que têm os primeiros contatos com a família dos mortos acabam sendo responsáveis por orientar sobre as medidas estabelecidas diante da pandemia. Nas redes sociais, as páginas do Facebook do perfil da PMSP e do SFMSP esforçaram-se para divulgar as novas normas e buscaram valorizar as conquistas em meio à crise para a população, como o trabalho incessante nos cemitérios sem maiores percalços. Ressaltam-se as iniciativas da comunicação da entidade com os órgãos da Administração Direta da prefeitura (algo pouco comum na trajetória da autarquia), convergindo esforços de atuação mediante reuniões intersecretariais que ocorreriam diariamente e a presença no Centro Integrado de Controle do Estado de São Paulo (CICC).

\subsection{0 fluxo de atividades}

Os desafios impostos ao SFMSP demandaram ações rápidas, de modo que as implicações da epidemia foram respondidas a contento na perspectiva organizacional, técnica e gerencial nos primeiros três meses da pandemia - entre meados de março e meados de junho. Em tese, o enfrentamento de um cenário mais catastrófico, à primeira vista, está amparado pelas medidas adotadas e pelos gatilhos existentes, como a previsão de ampliação do quadro de pessoal e/ou a montagem emergencial de novos centros logísticos, por exemplo.

Obviamente, dado o alto grau de imprevisibilidade da pandemia, a Casa de Máquinas deverá responder de novas maneiras, a depender das circunstâncias que se colocarem. Entretanto, para o período que ora analisamos neste artigo, pode-se afirmar que as funções administrativas foram realizadas nos bastidores, traduzindo as estratégias no nível tático-operacional para permitir a (re) adequação da prestação de serviços.

A interdependência das ações expostas e discutidas a partir das áreas-meio da gestão pública na SFMSP pode ser visualizada em um fluxo de atividades técnico-gerencial (Figura 2), ilustrando como as engrenagens da Casa de Máquinas trabalharam para operacionalizar um serviço público essencial; ressalvado que existem alguns processos nesse percurso que não foram tratados neste trabalho e, portanto, trata-se de um diagrama simplificado.

Por fim, sobre os 8 elementos fundamentais recomendados anteriormente no Quadro 1, muitas estratégias e ações foram incorporadas pelo SFMSP. Nos documentos oficiais, nota-se a ausência de menções à repatriação de corpos, algo talvez explicado por ser competência, a priori, do governo federal e não implicar uma prioridade perante o focusing event de mortes na localidade. 


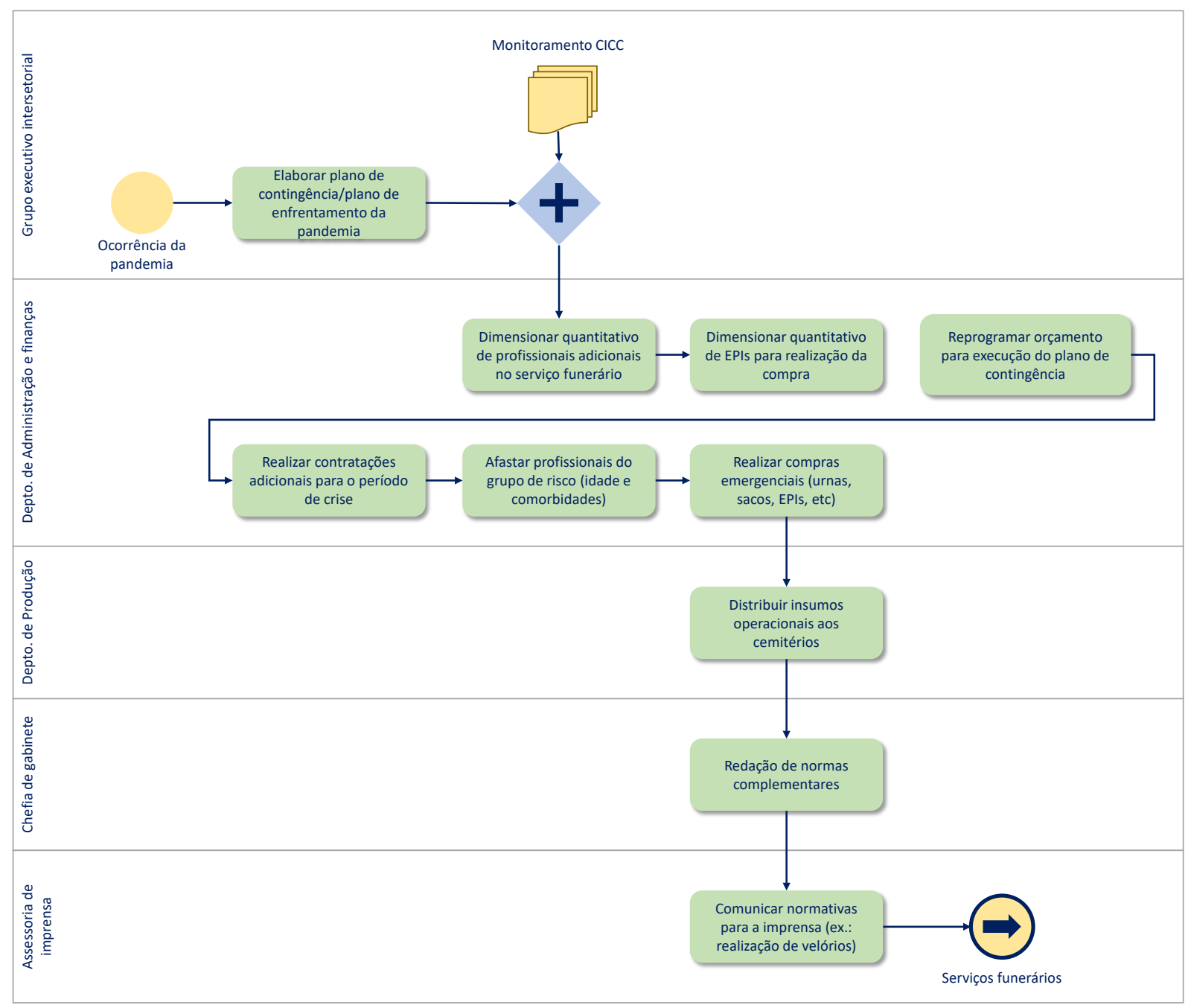

Fonte: Elaborada pelos autores.

\subsection{Por uma contribuição para as diferentes realidades das cidades}

Como a análise do SFMSP pode contribuir com realidades distintas? Essa é uma questão fulcral para se refletir, ao fim e ao cabo, sobre os aprendizados do município de São Paulo vis-à-vis o contexto de algumas capitais.

O caso paulistano evidencia a inevitabilidade de uma resposta imediata, ainda que reativa, por parte dos diversos elos da cadeia de combate à crise pandêmica. Consequentemente, a mobilização da casa de máquinas da administração pública torna-se premente para redimensionar a oferta dos serviços públicos essenciais. E, ainda que se busque evitá-la, a atenção aos serviços funerários tem sido constantemente demandada nos diferentes aglomerados urbanos em que os reflexos da COVID-19 foram sentidos. 
A Tabela 2 sinaliza o tamanho do problema em São Paulo e em outras 4 capitais do país com altos índices de mortalidade (óbitos por 100 mil habitantes), designando também como os serviços funerários são ofertados à população. ${ }^{4}$ Constatam-se 3 tipos de sistema: (i) execução direta pelo poder público, como o monopólio exercido na capital de São Paulo, em que apenas a autarquia municipal é a prestadora do serviço; (ii) execução pela iniciativa privada, como na cidade do Rio de Janeiro, com a concessão da prefeitura para empresas; e (iii) a execução tanto pelo poder público quanto pela iniciativa privada, em um modelo híbrido, como nas capitais do Ceará, Pernambuco e Amazonas.

\section{TABELA 2 CAPITAIS BRASILEIRAS COM ALTO NÚMERO DE ÓBITOS POR COVID-19}

\begin{tabular}{|c|c|c|c|c|c|}
\hline Município & São Paulo & Rio de Janeiro & Fortaleza & Recife & Manaus \\
\hline$N^{0}$ habitantes ${ }^{*}$ & 12.252 .023 & 6.718 .903 & 2.669.342 & 1.645 .727 & 2.182 .763 \\
\hline Total de casos & 69.347 & 32.951 & 25.726 & 1.5977 & 18.981 \\
\hline Óbitos & 4.675 & 4.055 & 2.334 & 1.120 & 1.390 \\
\hline Óbitos/100mil hab & 38,2 & 60,4 & 87,4 & 68,1 & 63,7 \\
\hline Sistema funerário & Público** & Privado & Híbrido & Híbrido & Híbrido \\
\hline
\end{tabular}

Nota: Extração de dados da base Dataglass - COVID-19 - Brasil, com dados atualizados até o dia 02 de junho de 2020. ${ }^{*}$ População estimada conforme Instituto Brasileiro de Geografia e Estatística (IBGE, 2019). **Sistema público, mas com a flexibilização para empresas privadas atuarem no período da pandemia.

Fonte: Elaborada pelos autores.

De qualquer maneira, independentemente do tipo de prestação do serviço funerário, a Casa de Máquinas da administração pública é acionada para responder aos efeitos da crise. No caso de monopólio estatal, amplamente explorado neste trabalho, a ação deve ser mais imediata, justamente porque o poder público é o único ofertante do serviço. No caso do modelo de concessão sem a participação do poder público na oferta, o back office governamental também é fundamental, com ações de monitoramento e controle da prestação do serviço; na cidade do Rio de Janeiro, por exemplo, diante dos reflexos da pandemia na população mais carente, foram usadas cláusulas contratuais dos acordos firmados junto à iniciativa privada para garantir a gratuidade dos serviços à população hipossuficiente e criar tarifas sociais, neste último caso independentemente da condição social, conforme Decreto 47.418, de 7 de maio de 2020. Já no caso de modelos híbridos, há a necessidade de uma máquina pública atuante nas duas frentes, acompanhando as ações desempenhadas pela iniciativa privada e garantindo o bom funcionamento do serviço público; em Manaus-AM, frente ao elevado número de óbitos, as demandas do serviço público denominado SOS Funeral exigiram o redimensionamento de sua capacidade de atendimento, requerendo a plena atuação da Casa de Máquinas.

\footnotetext{
${ }^{4}$ No que pese este artigo não ter como objetivo a discussão acerca da tipificação dos serviços funerários como serviços públicos, cabe mencionar as duas interpretações dos tribunais acerca dos regimes de prestação desse serviço: há jurisprudência tanto sobre a validade do monopólio estatal, com execução direta ou concessão para iniciativa privada, quanto a favor da livre iniciativa econômica, não cabendo ao poder público a permissão para tal atividade (Miranda, 2011).
} 
Em linhas gerais, o que assemelha os três modelos de prestação do serviço é a resposta esperada da Casa de Máquinas, seja na consideração dos efeitos da crise no sistema funerário desde os planos de contingenciamento, seja na articulação com os entes privados na busca por melhor atendimento à sociedade, seja na reestruturação do serviço público para atender à demanda inesperada. Em todas as situações, faz-se necessário resgatar os pontos-chave do Quadro 1, adaptando-os para cada contexto.

Sob a ótica do caso do SFMSP, os projetos e as atividades de adequação à realidade imposta viabilizaram os esforços de coordenação de ações com outras organizações públicas, inclusive no âmbito estadual, o redimensionamento dos recursos financeiros e humanos, as compras de equipamentos emergenciais, o aumento da capacidade operacional dos sepultamentos, a ampliação dos canais de comunicação e a flexibilização do monopólio público.

\section{CONSIDERAÇÕES FINAIS}

Muitas são as dimensões e os fatores a serem considerados pela administração pública para responder a uma crise sanitária com impactos econômicos e efeitos sociais, como a da COVID-19. Neste artigo, deslocando-se da análise do sistema político-estrutural caracterizado pelos 3Ps - polity, politics e policy -, focamos a dimensão intraorganizacional da gestão pública, formada pelas áreas-meio e suas funções administrativas na tradução das decisões estratégicas em ações tático-operacionais.

Preenchendo uma lacuna de descrição e análise das funcionalidades (e das atividades) de retaguarda de um serviço público subexplorado pelos acadêmicos de gestão e políticas públicas no país, como o funerário, o artigo demonstrou a reestruturação de um serviço funerário que é monopólio estatal no decurso da pandemia. O framework da Casa de Máquinas, como subsistema técnico-gerencial intraorganizacional da gestão pública, foi caracterizado como "motor" para o delivery do SFMSP com: (i) incremento financeiro, com a suplementação de recursos para custear as ações; (ii) redimensionamento da força de trabalho, com contratações emergenciais e movimentação de servidores; (iii) desenho de processos, convergindo esforços com outros órgãos, além da flexibilização do monopólio estatal; (iv) novas contratações, usando-se dos recursos disponíveis e das autorizações legais para realizar compras e contratos emergenciais; (v) rearranjos logísticos e operacionais, com a criação de centros logísticos e ampliação da capacidade operacional; e (vi) estratégias de comunicação, visando a transmitir informações mais assertivas para os funcionários públicos envolvidos na prestação dos serviços e para as famílias que perderam seus entes. Todas essas ações funcionaram como "roldanas e engrenagens" para a operacionalização do serviço funerário, evitando seu colapso.

A falta de diretrizes estratégicas e de planos de ação para enfrentamento de situações emergenciais denota o viés reativo da readequação do SFMSP, distante de um cenário ideal, ainda que as ações desempenhadas na crise do coronavírus estejam pari passu com as recomendações de organismos internacionais. Entretanto, é elementar destacar que, sem o devido planejamento prévio, a pressão imposta sobre a estrutura da administração pública para uma resposta governamental imediata pode redundar em uma série de disfuncionalidades e no não alcance dos resultados esperados, como amplamente divulgado pela mídia em outras localidades do Brasil e do mundo.

Naturalmente, como o texto joga luz em um processo em curso, o exame realizado carece de entrevistas em profundidade com atores-chave de cada área-meio, as quais possibilitariam compreender as capacidades administrativas e também os possíveis contratempos como, por exemplo, as dificuldades com as inflexões políticas que alteraram as estratégias e os "furos de estoque" dos 
materiais adquiridos e que os fornecedores tardaram a entregar; enfim, situações que comprometem a operação da Casa de Máquinas. Essa metáfora e seu framework foram esboçados originalmente neste artigo para esclarecer como as áreas funcionais de um governo ou organização pública contribuíram para mitigar as consequências da COVID-19 no sistema funerário. A metáfora deve ser refinada e pode ser replicada para descrever e analisar o back office da prestação de quaisquer serviços públicos, analisando-se o seu micromanagement. Considerando a secundarização da dimensão intraorganizacional e de sua natureza técnico-gerencial na agenda de pesquisa da administração pública nacional, espera-se sua revalorização nas investigações sobre capacidades e recursos a partir de um focus de public management.

Sobre o locus empírico, o SFMSP, que até então era evitado no debate público e considerado não estratégico institucionalmente, vide os planos de concessão (e mesmo o uso dos cargos pelo Executivo para as articulações de governos de coalizão com partidos políticos), de uma hora para outra ganhou relevância e ocupou um grande espaço na agenda governamental, requerendo ações de curto e médio prazo, como as aquisições e estruturas temporárias, e também de longo prazo, como a construção de um cemitério vertical. Caso o plano de concessão seja reconsiderado e não se concretize, é condição sine qua non um upgrade na profissionalização da burocracia de médio escalão e da direção pública dessa autarquia municipal. Um indício para essa sugestão é que, durante a pandemia, foi imperativa a designação de muitos servidores públicos externos à estrutura organizacional do serviço funerário municipal para delinear as estratégicas emergenciais e guiar os processos gerenciais; como relatado no Quadro 2, vários dos cargos de direção e assessoramento da entidade são loteados politicamente e, por conseguinte, são ocupados por agentes públicos sem as competências para a gestão dessa organização pública. 


\section{REFERÊNCIAS}

Barzelay, M. (2003). La Nueva Gestión Pública: un acercamiento a la investigación y al debate de las políticas. México, DF: Fondo de Cultura Económica.

Castro, L. M. (2014, 6 de abril). TCM reprova conta do Serviço Funerário. O Estado de São Paulo. Recuperado de https://sao-paulo.estadao.com. $\mathrm{br} /$ noticias/geral,tcm-reprova-conta-do-servicofunerario, 1150225

Cavalcanti, B. S. (2004). Da modelagem à improvisação: reinterpretando a modelagem organizacional. Revista de Administração Pública, 38(4), 589-611.

Coelho, F. S., \& Valadares, J. L. (2019). Editorial: Dimensões Intraorganizacionais e Funções Gerenciais no Setor Público. Revista de Administração Pública e Gestão Social, 11(4), 1-4.

Dataglass. (2020). Covid-19 - Brasil. São Paulo, SP: Autor.

Decreto $n^{\circ}$. 59.283, de 16 de março de 2020. (2020). Declara situação de emergência no Município de São Paulo e define outras medidas para o enfrentamento da pandemia decorrente do coronavírus. São Paulo, SP.

Decreto $n^{\circ} .59 .358$, de 15 de abril de 2020. (2020). Cria Grupo Executivo Intersecretarial com o objetivo de planejar, propor, acompanhar e articular as ações relativas aos procedimentos preparatórios e de realização das inumações decorrentes de óbitos pela Covid-19. São Paulo, SP.

Decreto $n^{\circ}$. 64.880, de 20 de março de 2020. (2020). Dispõe sobre a adoção, no âmbito das Secretarias da Saúde e da Segurança Pública, de medidas temporárias e emergenciais de prevenção de contágio pelo COVID-19. São Paulo, SP.

Decreto $n^{\circ}$. 47.418, de 07 de maio de 2020. (2020). Estabelece procedimentos para acesso aos benefícios de gratuidade para pessoas declaradas hipossuficientes, e para arrendamento de jazigo e cremação sociais, e dá outras providências. Rio de Janeiro, RJ.

Denhardt, R. B. (2008). Theories of Public Organization (5th ed.). Belmont, CA: Thomson Wadsworth.

Ferlie, E., Lynn, L., Jr., \& Pollitt, C. (Ed.) (2007). The Oxford Handbook of Public Management. New York, NY: Oxford University Press.
Finegan, O., Fonseca, S., Pierre, G. H., Mendez, M. D. M., Gonzalez, J. R., Tidball-Binz, M., Winter, K. A. ... ICRC Advisory Group on the Management of COVID-19 Related Fatalities (2020). International committee of the red cross (ICRC): general guidance for the management of the dead related to COVID-19. Forensic Science International: Synergy, 2, 129-137. Recuperado de https://doi.org/10.1016/j. fsisyn.2020.03.007

Huerta, A. R. (2008). Una ruta metodológica para evaluar la capacidad institucional. Política y cultura, 30, 119-134. Recuperado de http://www.scielo. org.mx/scielo.php?script=sci_arttext $\&$ pid $=$ S018877422008000200006\&lng=es\&tlng=es

Instituto Brasileiro de Geografia e Estatística. (2019). IBGE Cidades. Brasília, DF: Autor. Recuperado de https://cidades.ibge.gov.br/

Lei $n^{\circ}$ 13.979, de 6 de fevereiro de 2020. (2020). Dispõe sobre as medidas para enfrentamento da emergência de saúde pública de importância internacional decorrente do coronavírus responsável pelo surto de 2019. Brasília, DF. Recuperado de http://www.planalto.gov.br/ccivil_03/_ato20192022/2020/lei/L13979.htm

Lynn, L. E. (2007). Public Management. In Peters, B. G. \& Pierre, J. (Org.), Handbook of Public Administration: Concise Paperback Edition (Cap. 1, pp. 13-23). London, UK: Sage Publications.

McGuire, M., \& Schneck, D. (2010). What if Hurricane Katrina hit in 2020? The need for strategic management of disasters. Public Administration Review, 70, 201-207.

Ministério da Saúde (2020). Manejo de corpos no contexto do novo coronavírus - COVID-19. Brasília, DF: Autor. Recuperado de https://www.saude.gov. br/images/pdf/2020/marco/25/manejo-corposcoronavirus-versao1-25mar20-rev5.pdf

Miranda, G. M. (2011). Serviços funerários e livre iniciativa econômica (Monografia). Escola de Formação da Sociedade Brasileira de Direito Público, São Paulo, SP. Recuperado de http://www. sbdp.org.br/wp/wp-content/uploads/2018/03/180_ Monografia-Gabriel.pdf

Morgan, G. (1996). Imagens da organização: edição executiva. São Paulo, SP: Atlas.

New York City. (2020). Covid-19: Data. Nova York, NY: Autor. Recuperado de: https://www1.nyc.gov/ site/doh/covid/covid-19-data.page 
Ollaik, L. G. \& Ziller, H. M. (2012, February 09). Concepções de validade em pesquisas qualitativas. Educação e Pesquisa, 38(1), 229-242. Recuperado de https://doi.org/10.1590/S1517-97022012005000002

Paiva, F. G., Jr., Leão, A. L. M. S. \& Mello, S. C. B. (2011). Validade e confiabilidade na pesquisa qualitativa em administração. Revista de Ciências da Administração, 13(31), 190-209.

Polícia Civil do Estado de São Paulo. (2020). Conhecendo o Centro Integrado de Comando e Controle (CICC) e suas funções. São Paulo, SP: Autor.

Porfírio, F. (2006, 24 de fevereiro). Condenada quadrilha que agia no serviço funerário de SP. Consultor Jurídico. Recuperado de https://www. conjur.com.br/2006-fev-24/condenada_quadrilha agia_servico_funerario_sp

Prefeitura de São Paulo. (2020). Prefeitura de São Paulo apresenta plano de contingência e novas medidas para Serviço Funerário. São Paulo, SP: Autor. Recuperado de http://www.capital.sp.gov.br/ noticia/prefeitura-de-sao-paulo-apresenta-planode-contingencia-e-novas-medidas-para-servicofunerario

Resolução SS-32, de 20 de março de 2020. (2020). Dispõe sobre as diretrizes para manejo e seguimento dos casos de óbito no contexto da pandemia COVID-19 no Estado de São Paulo. São Paulo, SP.

Rodrigues, A. (2019, 24 de julho). Serviço funerário de SP tem osso amontoado, limusine parada e desperdício. Folha de São Paulo. Recuperado de https://www1.folha.uol.com.br/cotidiano/2019/07/ servico-funerario-de-sp-tem-osso-amontoadolimusine-parada-e-desperdicio.shtml

Sindicato dos Trabalhadores na Administração Pública e Autarquias no Município de São Paulo. (2019, 19 de junho). Privatização/Concessão do SFMSP. Recuperado de https://www.sindsep-sp.org. $\mathrm{br} /$ noticias/funcionalismo/privatizacao-concessaodo-sfmsp-4942

Tribunal de Contas do Município de São Paulo. (2020, 14 de maio). Prefeitura de São Paulo adia pela quarta vez privatização de cemitérios. Recuperado de https://portal.tcm.sp.gov.br/Pagina/17332

Wahrlich, B. M. S. (1979). Evolução das ciências administrativas na América Latina. Revista de Administração Pública, 13(1), 31-68.

Zavattaro, S.M. (2020). "We've Cared for the Dead since We Started Caring": COVID -19 and Our Relationship to Public and Private Deathcare. Public Admin Rev, Early View, 1-5. Recuperado de http:// doi:10.1111/puar.13221 


\section{Fernando de Souza Coelho}

https://orcid.org/0000-0003-2803-0722

Doutor em Administração Pública pela Escola de Administração de Empresas de São Paulo da Fundação Getulio Vargas (FGV EAESP); Professor da Universidade de São Paulo (EACH-USP). E-mail: fernandocoelho@usp.br

\section{Victor Corrêa}

https://orcid.org/0000-0002-9223-1214

Doutor em Administração pela Universidade de São Paulo (FEARP-USP); Professor da Academia da Força Aérea. E-mail: prof.victorcorrea@gmail.com

\section{Rafael Lincoln Lisboa}

(1)

https://orcid.org/0000-0002-0567-8625

Mestrando em Gestão de Políticas Públicas pela Universidade São Paulo (EACH-USP).

E-mail: rafa.gpp@gmail.com

\section{Sibelly Resch}

https://orcid.org/0000-0001-8542-4299

Doutora em Administração pela Universidade Municipal de São Caetano do Sul (USCS); Professora da Universidade Federal de Mato Grosso do Sul (UFMS), campus Naviraí. E-mail: sibellyresch1@gmail.com 